Provided for non-commercial research and education use. Not for reproduction, distribution or commercial use.

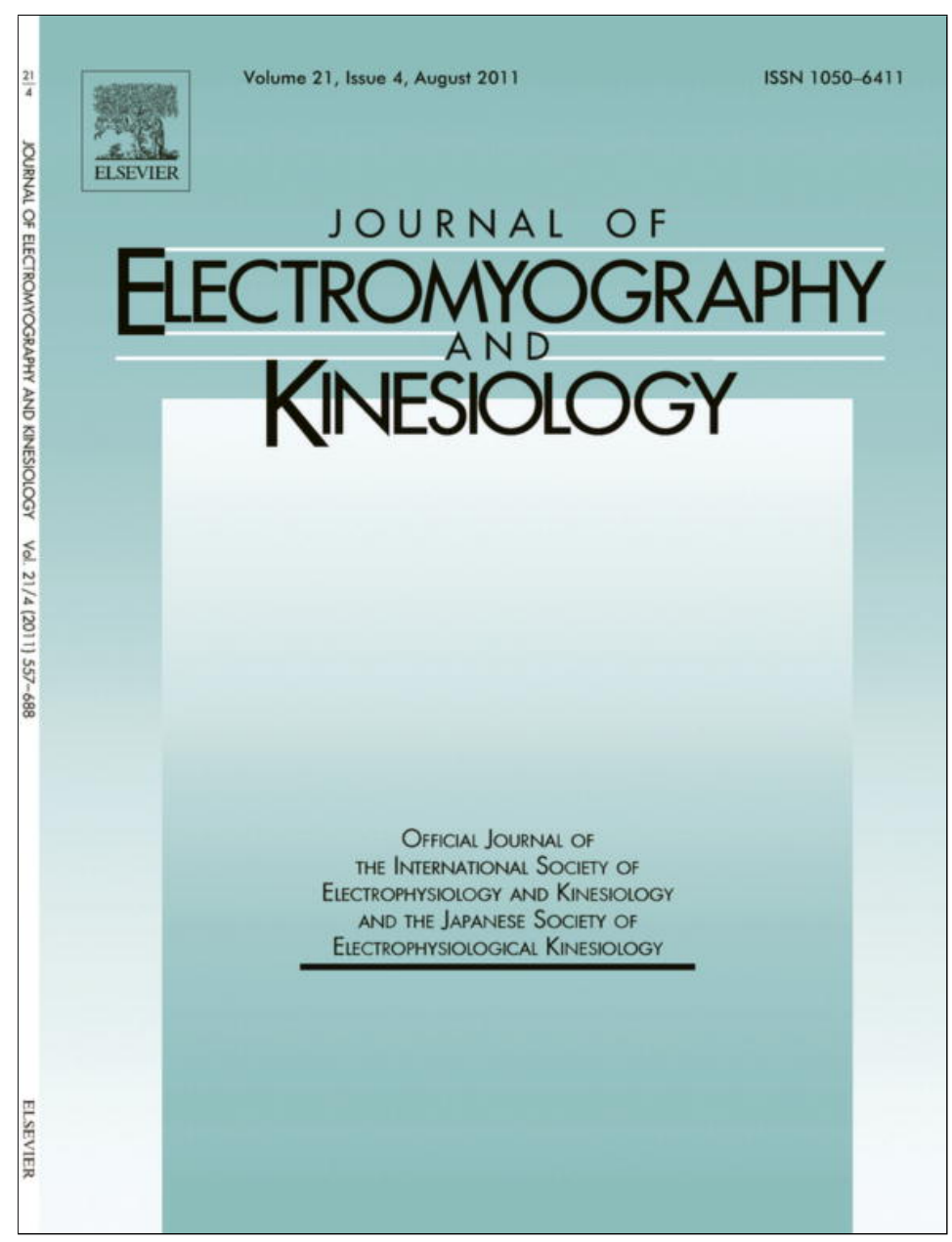

This article appeared in a journal published by Elsevier. The attached copy is furnished to the author for internal non-commercial research and education use, including for instruction at the authors institution and sharing with colleagues.

Other uses, including reproduction and distribution, or selling or licensing copies, or posting to personal, institutional or third party websites are prohibited.

In most cases authors are permitted to post their version of the article (e.g. in Word or Tex form) to their personal website or institutional repository. Authors requiring further information regarding Elsevier's archiving and manuscript policies are encouraged to visit:

http://www.elsevier.com/copyright 


\title{
A comparison of training intensity between whole-body vibration and conventional squat exercise
}

\author{
Pedro J. Marín a,b,*, Alejandro Santos-Lozano ${ }^{c}$, Fernanda Santin-Medeiros ${ }^{c}$, Christophe Delecluse ${ }^{\mathrm{d}}$, \\ Nuria Garatachea ${ }^{c}$ \\ ${ }^{a}$ Laboratory of Physiology, European University Miguel de Cervantes, Valladolid, Spain \\ ${ }^{\mathrm{b}}$ Research Center on Physical Disability, ASPAYM Castilla y León, Spain \\ ${ }^{\mathrm{c}}$ Institute of Biomedicine (IBIOMED), University of León, León, Spain \\ ${ }^{\mathrm{d}}$ Department of Biomedical Kinesiology, Faculty of Kinesiology and Rehabilitation Sciences, Katholieke Universiteit Leuven, Belgium
}

\section{A R T I C L E I N F O}

\section{Article history:}

Received 23 September 2010

Received in revised form 2 December 2010

Accepted 28 December 2010

\section{Keywords:}

EMG

Lumbar activity

Acceleration

Perceived exertion

\begin{abstract}
A B S T R A C T
The aim of this study was to investigate surface electromyographic activity (sEMG) and rate of perceived exertion (RPE) during semi-squat exercise on vibration platform compared with semi-squat exercise performed on a Smith machine. Twenty-three recreationally active students ( 15 males and 8 females) were exposed to six different loads in one of both exercise modes: vibration or Smith machine. The subject performed a squat in six experimental conditions; the load differed per experimental condition. For each subject the exercise mode $(n=2)$ and the different loads per mode $(n=6)$ were assigned in a random order to check the influence of vibration magnitude (acceleration: $\mathrm{m} \mathrm{s}^{-2}$ ) as well as weight ( $\mathrm{kg}$ ) on sEMG and RPE. Two-way ANOVA for RPE, lumbar and lower-body sEMG revealed a significant weight main effect $(P<0.01)$ and a significant acceleration main effect $(P<0.01)$. The results from this study demonstrate that the training stimulus resulting from an isometric semi-squat exercise on a vibration platform (acceleration: from 12 to $89 \mathrm{~m} \mathrm{~s}^{-2}$ ) is similar to the training stimulus of an isometric semi-squat exercise on Smith machine (weight: from 20 to $70 \mathrm{~kg}$ ) according to lower-body SEMG and RPE. However, the impact of semi-squat on vibration platform exercise for lumbar muscle is relatively small compared with semi-squat on Smith machine.
\end{abstract}

Crown Copyright (c) 2011 Published by Elsevier Ltd. All rights reserved.

\section{Introduction}

The squat is one of the most popular exercises to develop muscle strength of the lower limbs. The squat exercise can be performed in unloaded conditions, but to guarantee an optimal training intensity, squatting is mostly executed with an additional load by means of free weights, cable machine, Smith machine, vibration platform, etc. The variation in training stimulus during squat exercise that was performed in different conditions or on specific devices has been studied by several authors (McCurdy et al., 2010; Roelants et al., 2006; Schwanbeck et al., 2009). Anderson and Behm (2005) compared surface electromyographic activity (sEMG) of the soleus, vastus lateralis, biceps femoris, abdominal stabilizers, upper lumbar erector spinae, and lumbosacral erector spinae muscles during squat exercises using free weights and the Smith machine. They found that sEMG of the trunk musculature was the highest $(P<0.05)$ during the free weight

* Corresponding author at: Laboratory of Physiology, European University Migue de Cervantes, C/Padre Julio Chevalier 2, 47012 Valladolid, Spain. Tel.: +34 983 228508; fax: +34983278958.

E-mail address: pjmarin@uemc.es (P.J. Marín). squat; however, sEMG of the vastus lateralis was the highest during the Smith machine squats.

Recently, there has been a growing interest in the training effects of squat exercise executed on a vibrating platform. This method is called 'whole-body vibration' (WBV) and is considered to be beneficial in training (Delecluse et al., 2003; Marin and Rhea, 2010a,b; Petit et al., 2010) and rehabilitation (Bogaerts et al., 2009; Machado et al., 2010; Totosy de Zepetnek et al., 2009). Earlier research indicated that direct mechanical vibrations applied to the muscle belly elicit reflex muscle contractions, resulting into a 'tonic vibration reflex' (TVR), mediated by mono- and poly-synaptic pathways (Gillies et al., 1971a,b; Kossev et al., 2001). Muscle spindle Ia reflexes have been indicated as the major determinant of this vibration-induced neuromuscular activation leading to the TVR (Burke and Gandevia, 1995). In contrast to these direct vibrations, WBV-exercise consists mainly of squat exercises performed on a vibration platform that evokes a mechanical oscillation. The upand downward acceleration of the platform depends on the amplitude $(\mathrm{mm})$ and the frequency $(\mathrm{Hz})$ of the oscillation. The training stimulus during WBV is determined by the magnitude of the acceleration (Marin and Rhea, 2010a,b; Petit et al., 2010). Considering the numerous possible combinations of amplitude and frequency 
with the current technology, there is a need for scientific studies that analyze the responses during vibration exercise to elicit adequate responses and to achieve optimal training effects.

One study analyzed differences in leg muscle activity within a variation of squat exercises performed on a vibrating platform (Roelants et al., 2006). The authors concluded that WBV (frequency of $35 \mathrm{~Hz}$ and amplitude of $2.5 \mathrm{~mm}$ ) resulted in an activation of the different leg muscles to a magnitude that varied between $12.6 \%$ and $82.4 \%$ of maximal voluntary contraction.

Research findings indicate that squat exercises, performed on a vibrating platform, increase the strength of the leg extensors to a similar extent as can be realized by means of conventional resistance exercise at moderate intensity (Delecluse et al., 2003). However to develop a structured training methodology by means of progressive loading through WBV, we need to understand how the magnitude of acceleration $\left(\mathrm{m} \mathrm{s}^{-2}\right)$ impacts on muscle activation and to compare this with the training stimulus of squat exercise through traditional loading $(\mathrm{kg})$. To the best of our knowledge, no study has compared neuromuscular effect of vibration exercise versus conventional resistance exercise at different loads. The aim of this study was to investigate muscle activation and rate of perceived exertion (RPE) during semi-squat exercise on vibration platform compared with semi-squat exercise performed on a Smith machine.

\section{Methods}

\subsection{Subjects}

Twenty-three recreationally active students (15 males and 8 females). The subjects' mean ( \pm SD) age, height, and weight were $24.3 \pm 2.3$ years; $174.5 \pm 8.3 \mathrm{~cm}$; and $69.9 \pm 8.1 \mathrm{~kg}$, respectively. Exclusion criteria were diabetes, epilepsy, gallstones, kidney stones, cardiovascular diseases, joint implants, recent thrombosis, as well as any musculoskeletal problems that could affect performance. Prior to data collection subjects were informed of the requirements associated with participation and provided written informed consent. Moreover, subjects were not allowed to change their sleeping, eating, or drinking habits throughout the duration of their participation to the study. The research project was conducted according to the Declaration of Helsinki and it was approved by the University Review Board for research involving human subjects.

\subsection{Exercise protocol}

Each participant attended two laboratory test sessions. Initially, the skin of the subject was prepared and SEMG electrodes were placed. Before testing, all subjects performed a standardized warm-up, consisting of a 5-min walking at $6 \mathrm{~km} \mathrm{~h}^{-1}$. After that, subjects were exposed to six different loads in one of both exercise modes: vibration (Fitvibe, GymnaUniphy NV, Bilzen, Belgium) or Smith machine (Nautilus NT 1800; Nautilus, Inc., Vancouver, WA, USA). In the vibration mode the training load is quantified by means of the acceleration of the platform $\left(\mathrm{m} \mathrm{s}^{-2}\right)$. On the Smith machine the different loads are determined by the weight $(\mathrm{kg})$ that rests on the subject's shoulders. The subject performed a squat in six experimental conditions; the load differed per experimental condition. For each subject the exercise mode $(n=2)$ and the different loads per mode $(n=6)$ were assigned in a random order to check the influence of vibration magnitude (acceleration: $\mathrm{m} \mathrm{s}^{-2}$ ) as well as weight $(\mathrm{kg})$ on sEMG and RPE. Load of each experimental condition is presented in Table 1. Each experimental condition lasted $15 \mathrm{~s}$, with $60 \mathrm{~s}$ of rest between each condition. The vibration and weight exercises were performed with the subjects standing with their feet, separated to shoulder-width, on the vibration platform or on the floor, respectively. The knee angle was pre-set at $30^{\circ}$
Table 1

Parameters for each exercise mode.

\begin{tabular}{|c|c|c|c|}
\hline \multicolumn{3}{|c|}{ Vibration exercise } & \multirow{2}{*}{$\begin{array}{l}\text { Weight exercise } \\
\text { Weight }(\mathrm{kg})\end{array}$} \\
\hline Frequency $(\mathrm{Hz})$ & Amplitude & Acceleration $\left(\mathrm{m} \mathrm{s}^{-2}\right)$ & \\
\hline 25 & Low & 12.5 & 20 \\
\hline 35 & Low & 20.2 & 30 \\
\hline 45 & Low & 30.9 & 40 \\
\hline 25 & High & 36.3 & 50 \\
\hline 35 & High & 60.1 & 60 \\
\hline 45 & High & 88.4 & 70 \\
\hline
\end{tabular}

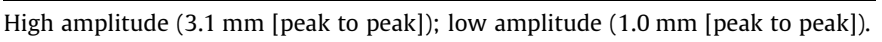

flexion. All subjects were asked to wear athletic shoes. All exercises were performed with a bar resting across the upper trapezius muscle. In the case of vibration exercise, an unloaded bar was used to maintain the same position during both exercises modes.

The vertical component of the acceleration of vibration platform was measured by means of an accelerometer in accordance with ISO2954, (Vibration meter, VT-6360, Hong Kong, China).

\subsection{Surface electromyographic activity (sEMG)}

Muscle activity of the vastus medialis (VM), vastus lateralis $(\mathrm{VL})$, biceps femoris long head (BF), medial gastrocnemius (MG), and lumbar paravertebral (LP) muscles were measured using sEMG. One set (two measuring electrodes and a reference electrode) of surface electrodes $(\mathrm{Ag} / \mathrm{AgCl}$, Skintact, Austria) was placed longitudinally to the muscle fibers direction approximately halfway from the motor point area to the distal part of the muscle. An inter-electrode distance of $2 \mathrm{~cm}$ was maintained. The reference electrode was placed in a neutral area away from the measuring electrodes. Before electrode placement, the area was cleaned with isopropyl alcohol, shaved and abraded in order to reduce skin impedance until it was lower than $5 \mathrm{k} \Omega$ (De Luca, 1997).

The surface electrodes were connected to a 14-bit AD converter (ME6000 Biomonitor, Mega Electronics, Kuopio, Finland). Raw EMG signals were pre-amplified close to the electrodes (gain of 375 , in the bandwidth of $8-500 \mathrm{~Hz}$ ) and sampled at $2000 \mathrm{~Hz}$ before being stored in a memory card (compact flash memory, $256 \mathrm{MB}$ ). On the basis of the frequency analysis, a band width of $\pm 0.8 \mathrm{~Hz}$ around each harmonic was excluded from the root-mean-square calculation (Abercromby et al., 2007). sEMG data analysis was performed across the use of specific software (MegaWin V 2.21, Mega Electronics, Kuopio, Finland). The middle $10 \mathrm{~s}$ of the exercise (from $2.5 \mathrm{~s}$ to $12.5 \mathrm{~s}$ ) were chosen for data analysis. sEMG raw data was averaged by root mean square in order to obtain averaged amplitude of the sEMG signal. The sEMG values were compared with equivalent baseline during unloaded squatting (no vibration and no weight), normalization relative to maximal voluntary contractions was unnecessary (Abercromby et al., 2007; Marin et al., 2009). Lower-body sEMG were calculated as the mean sEMG of $\mathrm{VM}, \mathrm{VL}, \mathrm{BF}$, and MG.

\subsection{Rating of perceived exertion (RPE)}

The OMNI-RES perceived exertion scale was verbally anchored (Robertson et al., 2003). OMNI-RES consists of 10 reporting options between 1 (extremely easy) to 10 (extremely hard). One week before the testing session, subjects attended two familiarization sessions, one for vibration exercises and one for weight exercises. Each subject was read a set of scale-specific instructions for the use of the OMNI-RES scale. For vibration exercises, participants were instructed to assign a rating of 1 to any perceptions of exertion that were less than those experienced during the semi-squat position (knee angle at $30^{\circ}$ flexion; without vibration) and a rating of 10 was associated with semi-squat position at the maximum vibration 
limit of the vibration platform $(60 \mathrm{~Hz}$, high amplitude $3.1 \pm 0.3 \mathrm{~mm}$ [peak to peak]). For weight exercise, participants were instructed according to Robertson et al. (2003).

\section{Experimental procedure}

To investigate the difference in muscle activation and RPE between a semi-squat exercise performed on a vibration platform or on a Smith machine, a randomized, crossover experimental design was used for this study. Each subject participated for four days in this study (two familiarization sessions and two test sessions). To reduce the impact of nocturnal changes on performance, testing of the individual subjects was standardized to approximately the same time of day.

\subsection{Statistical analysis}

Data were analyzed using SPSS software (Version 15.0 for Windows, Chicago, IL). All data were first examined visually and statistically for normality of distribution. Values are presented as means \pm standard deviation (SD). Significance level was set at $P \leqslant 0.05$.

A two-way ANOVA (exercise load by exercise mode) was performed to assess significant main effects and interactions on muscular activation lumbar and lower-body SEMG, and the RPE. A Bonferroni post hoc test was used in all pairwise comparisons when a significant result was found.

Agreement between exercise load (weight or acceleration), RPE lower body and lumbar SEMG was quantified by the Pearson correlation coefficient.

Linear regression analyses were used to study the relationship between lumbar or lower-body sEMG and exercise load (weight or acceleration). The slope of a linear regression line was used to calculate the rate of change in lumbar or lower-body sEMG when exercise load changed.

\section{Results}

Mean values \pm SD of RPE are given in Table 2 for each load exercise. The results of the two-way ANOVA for RPE revealed a significant exercise load main effect $(F 5,110=75.43, P<0.01)$ and a significant interaction effect ( $F 5,110=68.21, P<0.01$ ). The results for lumbar and lower-body sEMG are displayed in Fig. 1A and B.

Tables 3 and 4 display the correlation coefficients between the independent variables corresponding to weight and vibration exercises, respectively. A strong positive relationship was elicited between the training load (weight or acceleration) on the one hand and the muscle activation (lumbar sEMG, lower-body sEMG) and RPE on the other hand $(P \leqslant 0.01)$. All correlation coefficients were higher than 0.70 .

Lower-body sEMG (Fig. 2A) and lumbar sEMG (Fig. 2B) were modeled as a linear function of training load (weight or acceleration). The statistical significance $(P<0.01)$ of the linear regression parameters was noted. The regression line (Fig. 2A) between lower-body sEMG and training load for weight (or acceleration) conditions has an intercept of $8.18 \mathrm{~kg}\left(-4.55 \mathrm{~m} \mathrm{~s}^{-2}\right)$, and a slope of 0.35 (0.42). The regression line (Fig. 2B) between lumbar sEMG and exercise load for weight (or acceleration) conditions has an intercept of $17.89 \mathrm{~kg}\left(-4.07 \mathrm{~m} \mathrm{~s}^{-2}\right)$, and a slope of $0.20(0.94)$, respectively.

Linear regressions between lower body and lumbar sEMG is displayed in Fig. 3 for both exercise modes.

\section{Discussion}

To the best of our knowledge, this is the first study that analyzed muscle activation and rate of perceived exertion during squat
Table 2

Rating of perceived exertion (RPE) at each experimental condition.

\begin{tabular}{ll}
\hline & RPE \\
\cline { 2 - 2 } & Mean SD \\
\hline Weight $(\mathrm{kg})$ & \\
20 & $1.5 \pm 0.8$ \\
30 & $2.7 \pm 1.1^{*}$ \\
40 & $4.0 \pm 1.7^{*}$ \\
50 & $4.8 \pm 2.1^{*, \#}$ \\
60 & $5.3 \pm 2.2^{*, \#}$ \\
70 & $6.2 \pm 2.3^{*, \#, \&}$ \\
Acceleration $\left(\mathrm{m} \mathrm{s}^{-2}\right)$ & \\
12.5 & $1.5 \pm 1.1$ \\
20.2 & $2.4 \pm 1.6^{*}$ \\
30.9 & $3.3 \pm 1.8^{*}$ \\
36.3 & $3.8 \pm 1.6^{*}, \#$ \\
60.1 & $5.5 \pm 1.9^{*}, \#, \&, \%$ \\
88.4 & $6.4 \pm 1.9^{*, \#, \&, *}$
\end{tabular}

$P<0.01$ significantly different for $20 \mathrm{~kg}$ weight exercise or $12.5 \mathrm{~m} \mathrm{~s}^{-2}$ vibration exercise.

\# $P<0.01$ significantly different for $30 \mathrm{~kg}$ weight exercise or $20.2 \mathrm{~m} \mathrm{~s}^{-2}$ vibration exercise.

\& $P<0.01$ significantly different for $40 \mathrm{~kg}$ weight exercise or $30.9 \mathrm{~m} \mathrm{~s}^{-2}$ vibration exercise.

- $P<0.01$ significantly different for $50 \mathrm{~kg}$ weight exercise or $36.3 \mathrm{~m} \mathrm{~s}^{-2}$ vibration exercise.

exercise on vibration platform (acceleration; $\mathrm{m} \mathrm{s}^{-2}$ ) compared with Smith machine (weight; $\mathrm{kg}$ ). The primary finding of the present study is that an increase of acceleration by $1 \mathrm{~m} \mathrm{~s}^{-2}$ applied by the vibration platform results in increases of lower-body sEMG (mean sEMG of VM, VL, BF and MG) of $0.42 \%$, and $1 \mathrm{~kg}$ of additional weight on the Smith machine increases lower-body sEMG on average by $0.36 \%$. In other words, the training loads on the Smith machine and vertical vibration platform are proportionally related to each other with a ratio of $1 / 0.86$. This means that in this group of recreationally active students the lower-body sEMG during a semisquat on a vibration platform with an acceleration of $60 \mathrm{~m} \mathrm{~s}^{-2}$ almost equals the lower-body sEMG during a semi-squat on a Smith machine with $70 \mathrm{~kg}$ load.

A direct relationship between the intensity of exercise by weights and the percentage of maximal sEMG has been previously established (Adams et al., 1992; Clark et al., 2002). The results of this study confirm that the magnitude of vibrations (acceleration) has a clear positive correlation on lower body and lumbar muscle activation, as previously reported by Hazell et al. (2007).

Schwanbeck et al. (2009) have reported a 43\% higher muscle activation during the free weight squat compared to the Smith machine squat. Activation of the knee extensors and flexors and ankle plantar flexors were higher during free weight squat, whereas activation of the trunk stabilizers was similar across the two exercises. However, prior to this investigation, no study had attempted to compare between lumbar muscle activity during a semi-squat on a vibration platform and on a Smith machine. The data from this investigation indicate that there are remarkable differences in lumbar muscle activity between both exercise modes at similar lowerbody sEMG (Fig. 3). The data in Fig. 3 clearly indicate that a squat work-out that activates the lower body to the same extent on a vibration platform and on a Smith machine results in much lower activation the lumbar muscle using in the vibration condition.

At the moment, the mechanisms by which vibration acutely increases neuromuscular activity are still poorly understood. There are a few theories on how vibration stimuli can have effect on the neuromuscular system (Luo et al., 2005), such as a stimulation of Ia-afferents via spindle, resulting in facilitating homonymous $\alpha$-motor neurons, and the possible effects of vibration on the thixotropic properties of skeletal muscle and muscles spindles (Proske et al., 1993). Mechanical vibration of muscle induces a reflex, 

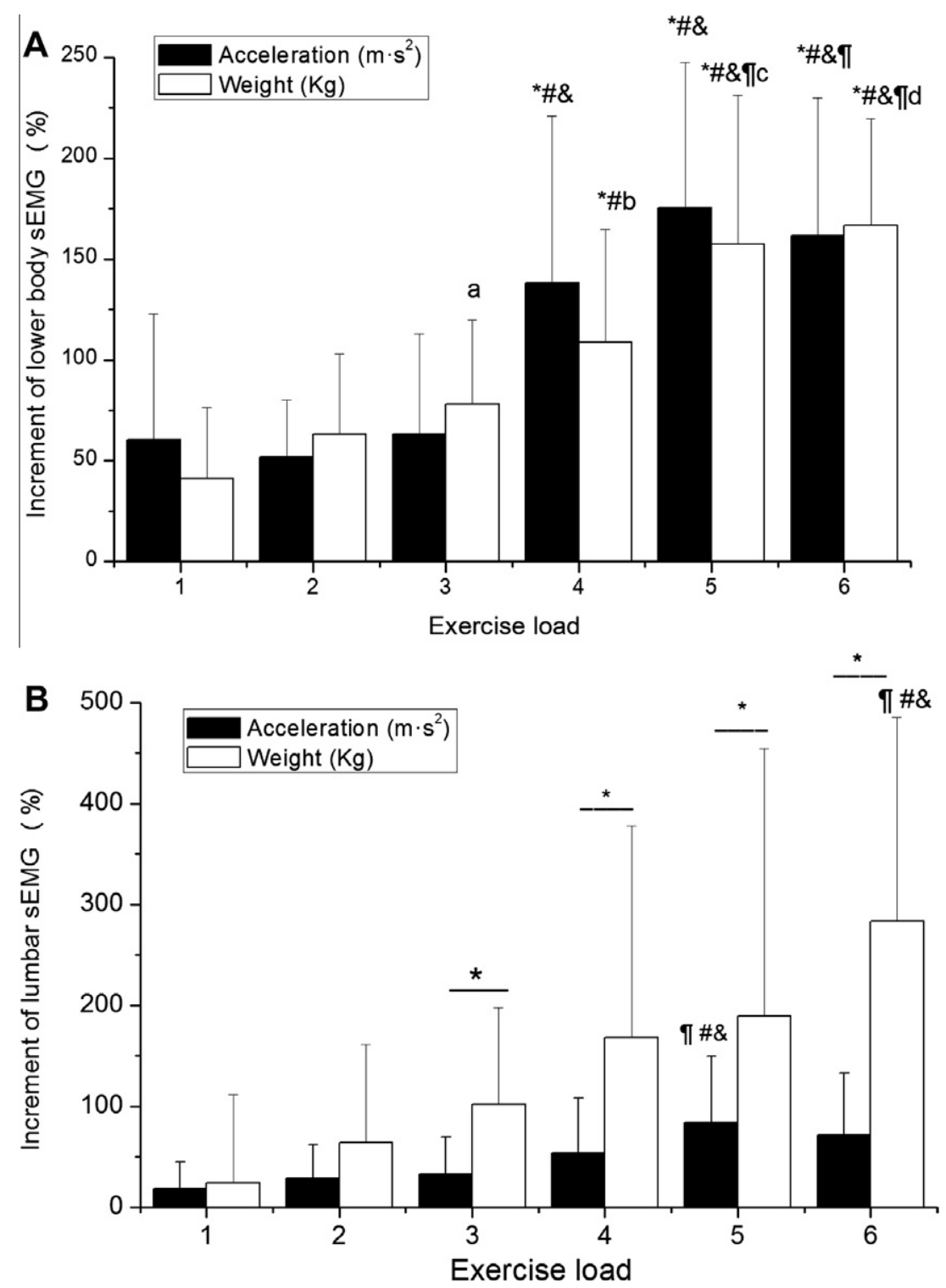

Fig. 1. Surface electromyography (sEMG) activity at each experimental condition. ${ }^{*} P<0.01$ significantly different for $20 \mathrm{~kg}$ weight exercise or $12.5 \mathrm{~m} \cdot \mathrm{s}^{-2}$ vibration exercise. \# $P<0.01$ significantly different for $30 \mathrm{~kg}$ weight exercise or $20.2 \mathrm{~m} \cdot \mathrm{s}^{-2}$ vibration exercise. \& $P<0.01$ significantly different for $40 \mathrm{~kg}$ weight exercise or $30.9 \mathrm{~m} \cdot \mathrm{s}^{-2}$ vibration exercise. $P<0.01$ significantly different for $50 \mathrm{~kg}$ weight exercise or $36.3 \mathrm{~m} \cdot \mathrm{s}^{-2}$ vibration exercise. ${ }^{\mathrm{a}} P<0.05$ significantly different for $30 \mathrm{~m} \cdot \mathrm{s}^{-2}$. ${ }^{\mathrm{b}} P<0.05$ significantly different for $36.3 \mathrm{~m} \cdot \mathrm{s}^{-2} .{ }^{c} P<0.05$ significantly different for $60.1 \mathrm{~m} \cdot \mathrm{s}^{-2}$. ${ }^{\mathrm{d}} P<0.05$ significantly different for $88.4 \mathrm{~m} \cdot \mathrm{s}^{-2}$. A: lower-body sEMG; B: lumbar sEMG.

\section{Table 3}

Pearson correlation coefficients among independent variables. Analyses were performed on data pooled from all weight conditions imposed. Rating of perceived exertion (RPE) and surface electromyography (sEMG) activity.

\begin{tabular}{llll}
\hline & RPE & $\begin{array}{l}\text { Increment of } \\
\text { lumbar sEMG (\%) }\end{array}$ & $\begin{array}{l}\text { Increment of lower } \\
\text { body sEMG (\%) }\end{array}$ \\
\hline Weight & $0.97^{*}$ & $0.97^{*}$ & $0.96^{*}$ \\
RPE & & $0.93^{*}$ & $0.89^{*}$ \\
Increment of & & & $0.92^{*}$ \\
$\quad$ lumbar sEMG (\%) & & \\
\hline$P<0.01$ & &
\end{tabular}

contraction (TVR) (Mileva et al., 2006). However, it has not clearly been demonstrated during WBV. On the other hand, vibration during exercise is thought to result in short-duration, small and rapid changes in the length of the muscle-tendon complex, in a fashion similar to simulated hypergravity. Several authors have demonstrated the RPE to be an effective method of qualifying resistance training (Day et al., 2004; Dishman et al., 1991; Gearhart et al., 2009). Duncan et al. (2006) reported that there were uniform
Table 4

Pearson correlation coefficients among independent variables. Analyses were performed on data pooled from all vibration conditions imposed. Rating of perceived exertion (RPE) and surface electromyography (sEMG) activity.

\begin{tabular}{llll}
\hline & RPE & $\begin{array}{l}\text { Increment of } \\
\text { lumbar sEMG (\%) }\end{array}$ & $\begin{array}{l}\text { Increment of lower- } \\
\text { body sEMG (\%) }\end{array}$ \\
\hline Acceleration & $0.95^{*}$ & $0.75^{*}$ & $0.70^{*}$ \\
RPE & & $0.87^{*}$ & $0.79^{*}$ \\
Increment of & & & $0.93^{*}$ \\
$\quad$ lumbar sEMG (\%) & & \\
${ }^{*} P<0.01$. & & \\
& & &
\end{tabular}

increases in RPE and SEMG in response to increases in resistance exercise intensity from $30 \%$ to $60 \%$ to $90 \%$ of 1 RM during a leg extension exercise. In the same sense, Lagally et al. (2002) indicated that monitoring RPE may be a useful technique for regulating resistance exercise intensity. According to our data, the magnitude of the correlations was very high for correlations between RPE, lower body sEMG and acceleration (Table 3), as well as RPE, lower body sEMG and weight (Table 4 ). In this sense, the results from this 

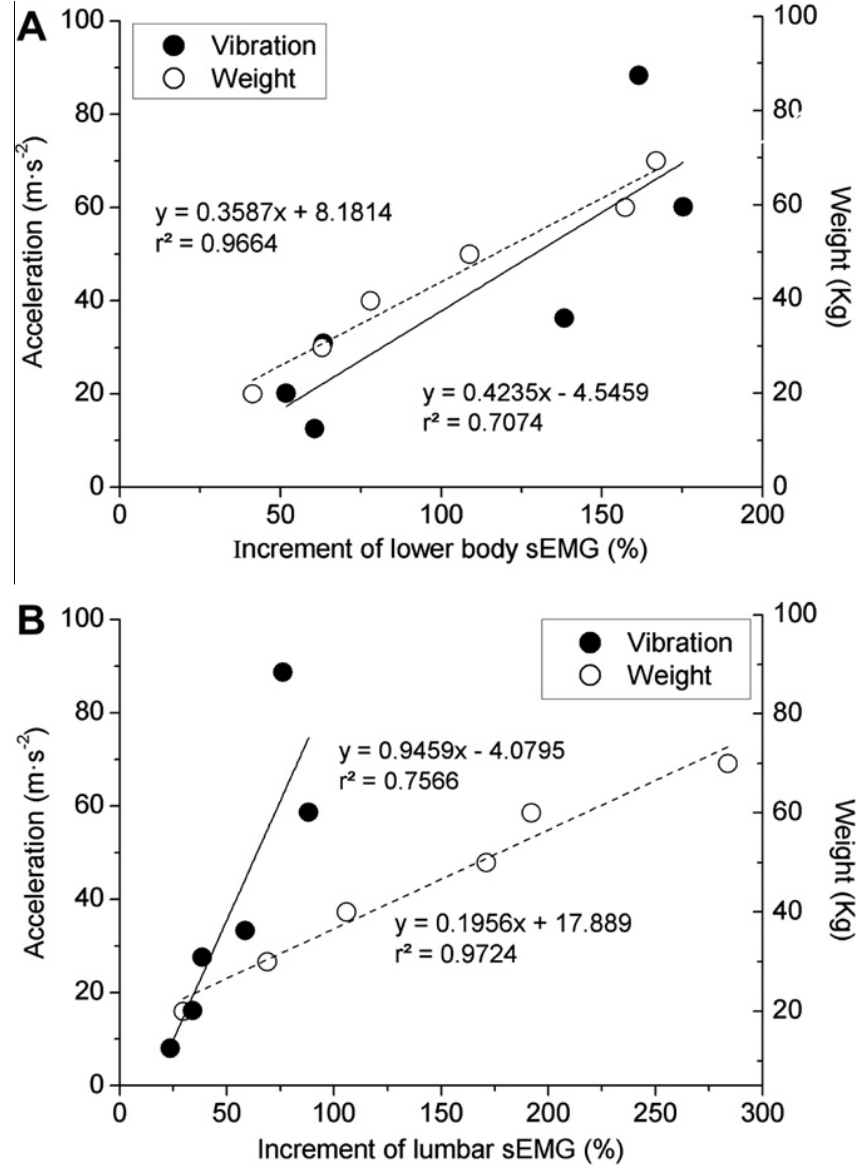

Fig. 2. Linear regression of external load versus surface electromyography activity (sEMG). Analyses were performed on separated data pooled from all two exercise modes imposed (external load of vibration exercises is acceleration $\left(\mathrm{m} \mathrm{s}^{-2}\right)(\mathbf{0})$; external load for weight exercises is kilogram $(\mathrm{kg})(\bigcirc)$. A: lower-body sEMG; B: lumbar sEMG.

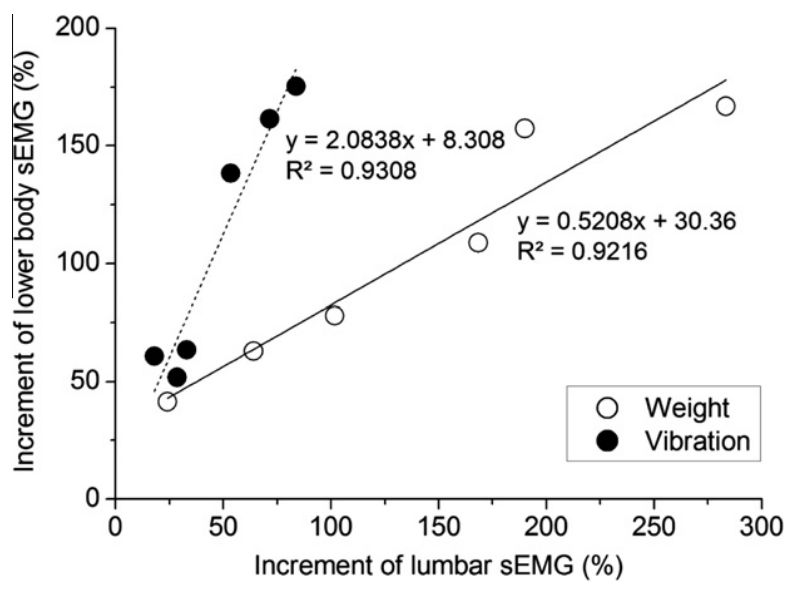

Fig. 3. Linear regression of lower body versus lumbar surface electromyography activity (sEMG). Analyses were performed on separated data pooled from all two exercise modes imposed (vibration exercise: $\bullet$; weight exercise: $\bigcirc$ ).

study suggest that using the RPE method after a vibration exercise would allow fitness professionals to assess the intensity levels that correspond to the level of the vibratory program.

In conclusion, the results from this study demonstrate that in young, recreationally active, adults the training stimulus resulting from an isometric semi-squat exercise on a vibration platform (acceleration: from 12 to $89 \mathrm{~m} \mathrm{~s}^{-2}$ ) is similar to the training stim- ulus of an isometric semi-squat exercise on Smith machine (weight: from 20 to $70 \mathrm{~kg}$ ) according to lower body sEMG and RPE. However, the impact of semi-squat on vibration platform exercise for lumbar muscle is relatively small compared with semi-squat on Smith machine. In addition, this study suggests that RPE method after a WBV exercise would allow the trainer to assess the intensity levels that correspond to the level of the vibratory program in healthy subjects.

These data suggest that for progression in training, exercise professionals can increase the training load by altering several variables, such as weight by means of $\mathrm{kg}$ in Smith machine or acceleration as a result of frequency and amplitude on vibration platform. Moreover, the vibration exercise could be a good strategy to train lower body muscles without an overload for lumbar muscle. Data also suggest that RPE method after a WBV exercise would allow trainer/therapist to assess the exercise loads that correspond to the level of the vibratory program in healthy subject.

\section{Conflict of interest statement}

None declared.

\section{Acknowledgements}

The authors thank the participants for their excellent cooperation.

\section{References}

Abercromby AF, Amonette WE, Layne CS, McFarlin BK, Hinman MR, Paloski WH. Variation in neuromuscular responses during acute whole-body vibration exercise. Med Sci Sports Exerc 2007;39(9):1642-50.

Adams GR, Duvoisin MR, Dudley GA. Magnetic resonance imaging and electromyography as indexes of muscle function. J Appl Physiol 1992;73(4):1578-83.

Anderson K, Behm DG. Trunk muscle activity increases with unstable squat movements. Can J Appl Physiol 2005;30(1):33-45.

Bogaerts AC, Delecluse C, Claessens AL, Troosters T, Boonen S, Verschueren SM. Effects of whole body vibration training on cardiorespiratory fitness and muscle strength in older individuals (a 1-year randomised controlled trial). Age Ageing 2009;38(4):448-54.

Burke D, Gandevia SC. The human muscle spindle and its fusimotor control. New York: Plenum Press; 1995

Clark BC, Manini TM, Mayer JM, Ploutz-Snyder LL, Graves JE. Electromyographic activity of the lumbar and hip extensors during dynamic trunk extension exercise. Arch Phys Med Rehabil 2002;83(11):1547-52.

Day ML, McGuigan MR, Brice G, Foster C. Monitoring exercise intensity during resistance training using the session RPE scale. J Strength Cond Res 2004;18(2):353-8.

De Luca C. The use of surface electromyography in biomechanics. J Appl Biomech 1997:2(13):135-63.

Delecluse C, Roelants M, Verschueren S. Strength increase after whole-body vibration compared with resistance training. Med Sci Sports Exerc 2003;35(6):1033-41.

Dishman RK, Graham RE, Holly RG, Tieman JG. Estimates of Type A behavior do not predict perceived exertion during graded exercise. Med Sci Sports Exerc 1991;23(11):1276-82.

Duncan MJ, Al-Nakeeb Y, Scurr J. Perceived exertion is related to muscle activity during leg extension exercise. Res Sports Med 2006;14(3):179-89.

Gearhart Jr RF, Lagally KM, Riechman SE, Andrews RD, Robertson RJ. Strength tracking using the OMNI resistance exercise scale in older men and women. J Strength Cond Res 2009;23(3):1011-5.

Gillies JD, Burke DJ, Lance JW. Supraspinal control of tonic vibration reflex. Neurophysiol 1971a;34(2):302-9.

Gillies JD, Burke DJ, Lance JW. The supraspinal control of the tonic vibration reflex. Proc Aust Assoc Neurol 1971b;8:143-6.

Hazell TJ, Jakobi JM, Kenno KA. The effects of whole-body vibration on upper- and lower-body EMG during static and dynamic contractions. Appl Physiol Nutr Metab 2007;32(6):1156-63.

Kossev A, Siggelkow S, Kapels H, Dengler R, Rollnik JD. Crossed effects of muscle vibration on motor-evoked potentials. Clin Neurophysiol 2001;112(3):453-6.

Lagally KM, Robertson RJ, Gallagher KI, Goss FL, Jakicic JM, Lephart SM, et al. Perceived exertion, electromyography, and blood lactate during acute bouts of resistance exercise. Med Sci Sports Exerc 2002;34(3):552-9 [discussion 560].

Luo J, McNamara B, Moran K. The use of vibration training to enhance muscle strength and power. Sports Med 2005;1(35):23-41. 
Machado A, García-López D, González-Gallego J, Garatachea N. Whole-body vibration training increases muscle strength and mass in older women: a randomized-controlled trial. Scand J Med Sci Sports 2010;20(2):200-7.

Marín PJ, Bunker D, Rhea MR, Ayllón FN. Neuromuscular activity during whole-body vibration of different amplitudes and footwear conditions: implications for prescription of vibratory stimulation. J Strength Cond Res 2009;23(8):2311-6.

Marin PJ, Rhea MR. Effects of vibration training on muscle power: a meta-analysis. J Strength Cond Res 2010a;24(3):871-8.

Marin PJ, Rhea MR. Effects of vibration training on muscle strength: a meta-analysis. J Strength Cond Res 2010b;24(2):548-56.

McCurdy K, O'Kelley E, Kutz M, Langford G, Ernest J, Torres M. Comparison of lower extremity EMG between the 2-leg squat and modified single-leg squat in female athletes. J Sport Rehabil 2010;19(1):57-70.

Mileva KN, Naleem AA, Biswas SK, Marwood S, Bowtell JL. Acute effects of a vibration-like stimulus during knee extension exercise. Med Sci Sports Exerc 2006;38(7):1317-28

Petit PD, Pensini M, Tessaro J, Desnuelle C, Legros P, Colson SS. Optimal whole-body vibration settings for muscle strength and power enhancement in human knee extensors. J Electromyogr Kinesiol 2010.

Proske U, Morgan DL, Gregory JE. Thixotropy in skeletal muscle and in muscle spindles: a review. Prog Neurobiol 1993;41(6):705-21.

Robertson RJ, Goss FL, Rutkowski J, Lenz B, Dixon C, Timmer J, et al. Concurrent validation of the OMNI perceived exertion scale for resistance exercise. Med Sci Sports Exerc 2003;35(2):333-41.

Roelants M, Verschueren SM, Delecluse C, Levin O, Stijnen V. Whole-bodyvibration-induced increase in leg muscle activity during different squat exercises. J Strength Cond Res 2006;20(1):124-9.

Schwanbeck S, Chilibeck PD, Binsted G. A comparison of free weight squat to Smith machine squat using electromyography. J Strength Cond Res 2009;23(9):2588-91.

Totosy de Zepetnek JO, Giangregorio LM, Craven BC. Whole-body vibration as potential intervention for people with low bone mineral density and osteoporosis: a review. J Rehabil Res Dev 2009;46(4):529-42.

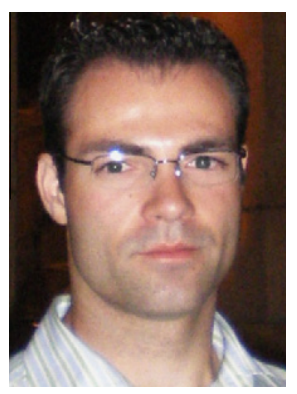

Pedro J. Marín completed a Ph.D. about vibration exercise at the European University of Madrid in Exercise Science in 2008. He has a BS in Exercise Science and also a BS in Physiotherapy. He has presented at national and international conferences. He has completed numerous studies in the area of vibration training, injury prevention, and overall fitness development. He has worked in personal training for many years. He has taught at A.T Still University (USA). He teaches at the European University Miguel de Cervantes and continues his work in physical therapy and investigation at the Research Center on Physical Disability, ASPAYM. In addition, he has developed different patents in the areas of vibration training, as well as muscular development. His research interests include vibration training and injury prevention.

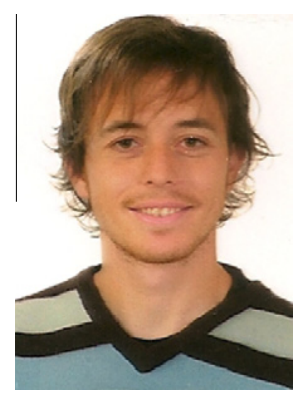

Alejandro Santos-Lozano received the degree in Primary Teacher Education as Physical Education Specialist in 2004, the degree in Physical Activity and Sport Science in 2010 and master degree in Innovation and Research in Science of Physical Activity and Sport in 2010 from the University of León, Spain. He is currently working on his Ph.D. investigating assessment tools for physical activity.

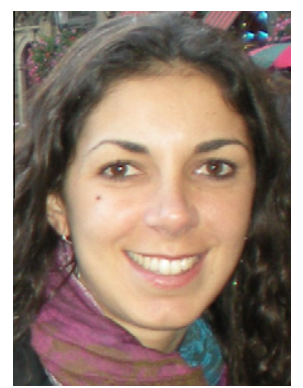

Fernanda Santin-Medeiros received a bachelor degree in Sport Sciences in 2005 from the University of Santa Catarina, Brazil. Thereafter she worked as a Pilates teacher in Brazil and Spain. She is currently working on her Ph.D. investigating acute and chronic effects of whole-body vibration exercise.

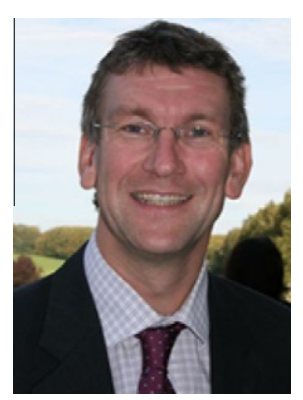

Christophe Delecluse, received his Ph.D. in Kinesiology in 1993 and works actually as full professor in the Department of Biomedical Kinesiology, Faculty of Kinesiology and Rehabilitation Sciences (K.U. Leuven, Belgium). His major research interest focuses on the effects of aging and exercise on muscle mass, muscle strength and neuromuscular performance. He has specific expertise in the field of interventions aiming for adaptations in force-velocity properties of skeletal muscle.

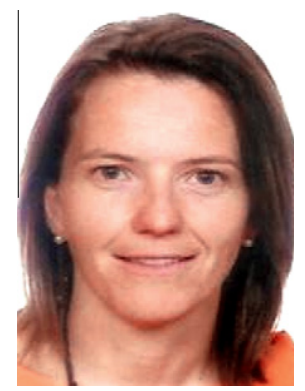

Nuria Garatachea received her Ph.D. in Physical Activity and Sports Sciences in 2002 from the University of León, León, Spain. She joined the University of León from 2004 to 2010 as Associate Professor, and currently is working at the Faculty of Health and Sport Science of the University of Zaragoza (Zaragoza, Spain) as Assistant Professor. Her major research interests are related to the physical activity and health as well as aging. 